\title{
Strength and Stiffness of 8-Inch and 12-Inch Deep Mixed Oak Bolt-Laminated Timber Mats
}

\author{
Rubin Shmulsky, ${ }^{\mathrm{a}}$ Dercilio Junior Verly Lopes, ${ }^{\mathrm{a}}$ Brunela Pollastrelli Rodrigues, ${ }^{\mathrm{b}}$ and \\ Gabrielly dos Santos Bobadilha ${ }^{\mathrm{a}, *}$
}

\begin{abstract}
Ground support provided by crane mats ensures the safety of workers and integrity of heavy-duty machines. Analytical evaluation of timber mats is necessary to advance the development of engineering standards associated with wood-based as well as other types of mats. The goal of this study was to mechanically evaluate bending stiffness and strength of timber 8 -inch and 12-inch deep mixed oak bolt-laminated timber mats. The 8-inch-deep specimen dimensions were 24 inches wide and 12 feet long, while 12-inch-deep specimens were 24 inches wide and 18 feet long. Twenty-eight specimens of each depth were flexurally tested over a 17:1 span to depth ratio. The modulus of elasticity along with the parametric and non-parametric design strength values are presented herein. The characterization of timber crane mats by analyzing their mechanical properties provides a starting point for producers and users to understand the performance and applications of their product. Further research will allow investigation of alternative materials, sizes, and structural designs.
\end{abstract}

Keywords: Mechanical properties; Access mats; Ground protection; Solid timber

Contact information: a: Department of Sustainable Bioproducts, Forest and Wildlife Research Center (FWRC), Mississippi State University, Mississippi State, MS, USA; b: Graduate Program of Forest Science, Southwestern Bahia State University, Bem Querer Drive, Vitoria da Conquista, 45083-900, Bahia State, Brazil; *Corresponding author: gd450@msstate.edu

\section{INTRODUCTION}

Timber mats and other types of access mats also called crane, dragline, construction, or environmental mats are used in heavy industrial construction. Construction equipment, such as loaders, trucks, bulldozers, cranes, draglines, are some of the equipment that benefit from the ability of access mats to spread relatively large and concentrated loads over great areas, thereby reducing ground pressure. They provide temporary stable surfaces in areas with limited access. This effort decreases rutting and soil disturbances as well as protects plant and biotic communities. The use of timber mats is intrinsically important on soft and or environmentally sensitive soils and areas that are more susceptible to degradation and erosion.

Crane mats are usually designed as temporary roadways, platforms, or bridges for pipeline installation, oil mining, electric power transmission, and general construction. They facilitate rapid site access before construction and through clean up and removal upon job completion. Ground support provided by mats ensures safety of workers, decreases impacts on soil, and provide foundational integrity for heavy-duty machines. To date, there has been limited and fragmented research on the mechanical evaluation of such crucial engineered products. Furthermore, research needs to be conducted to advance the development of engineering standards associated with wood-based as well as other types of mats. 
Several studies have been conducted in an effort to characterize the mechanical properties of crane mats. They described both development of new structures and characterization of flexural strength and stiffness of new or existing architectures. For instance, Herberg (2018) tested the performance of various configurations of naillaminated timber (NLT) manufactured from small diameter red oak in comparison with solid lumber crane mats. Shmulsky and Shi (2008) examined glue laminated billets for use in bolt-laminated mats. The glue laminated billets use low grade thin (4" $\times 4$ " thick) lumber and are essentially an engineered substitute for solid timber in mat applications. Yang et al. (2015) evaluated the performance of laminated pine lumber billets, where number 3 grade pine structural dimension lumber was prepared, face laminated as butt-jointed glulam, and tested in bending to determine bending strength and stiffness properties for potential use in access matting. This type of application provides a potential outlet and market for what is typically a relatively low-value material. Load sharing among bolt laminated billets was investigated by Shmulsky et al. (2008). This work is important because as machinery moves onto, off of, and near the edges of mats, their respective constituent members are not all loaded to the same degree at the same time.

The use of strain gauges, i.e., instrumented mats, during flexural loading was reported by Stroble III et al. (2012). More closely related to the work described herein was research completed by Owens et al. (2020), where mixed hardwood timber mats, of novel graded materials, were destructively tested. The relationship between these works is that the grading schema is the same. The raw material in this case is however mixed oak, rather than mixed hardwood. Also the work here describes mats of two distinct thicknesses (8and 12-inches). The work by Owens et al. (2020) also provides significant background on mat use, typical mat construction/architecture, and the grading or specification description for the timbers for both that work and the work described herein.

During the last approximately 5 years, mat producers, engineers, users and third party entities began addressing a potential standard grading requirement specific to mats. Mixed oak is one of the most common species groupings used in the matting industry. The study described herein evaluates the mechanical bending properties of bolt-laminated 8and 12-inch deep mats from mixed oak timbers that were graded per an experimental specification standard (Owens et al. 2020). The goal of this study was to mechanically evaluate the bending stiffness (modulus of elasticity, MOE as million psi) and strength (modulus of rupture, MOR as psi) performance of 8- and 12-inch deep bolt laminated mixed oak timber mats as well as statistically calculate the parametric and non-parametric $5^{\text {th }}$ percentiles and fiber stress in bending design, $F_{\mathrm{b}}$ of the experimental timber mats.

\section{EXPERIMENTAL}

\section{Materials and Methods}

Bolt laminated mats of mixed oak (red and white groups) were evaluated in this research. Per the NELMA (2017) standard, the mixed oak group includes the following species: black (Quercus velutina), cherrybark ( $Q$. falcata var. pagodaefolia), northern red (Q. rubra), southern red (Q. falcata), laurel (Q. laurifolia), pin ( $Q$. palustris), scarlet $(Q$. coccinea), water $(Q$. nigra), chestnut $(Q$. prinus), live $(Q$. virginiana), post $(Q$. stellate), swamp chestnut (Q. michauxii), white $(Q$. alba), bur (Q. macrocarpa), overcup ( $Q$. lyrata), and swamp white $(Q$. bicolor $)$. An experimental two tier grading system was documented based on the resources that are generally consumed in mat construction. This experimental 
grading or evaluation system is described in Owens et al. (2020). Once graded, square section timbers were bolted together, edge-to-edge, to form either 8- or 12-inch deep by 24-inch wide mats. Timbers and mats were considered green, i.e., not dried, at the time of manufacture and testing. Overall, 56 individual mat specimens were evaluated, 28 from the 8 -inch deep group and 28 from the 12-inch deep group.

In the case of the 8-inch deep specimens, each mat was comprised of three squaresection timbers (Fig. 1a). Each mat had 3 steel tension rods installed. Each timber was drilled with 1" diameter holes approximately at mid length and at five feet away from mid length in either direction. Then 3/4-inch diameter steel tension rods were located in the holes. For the 12-inch deep samples, each mat was comprised of two timbers, according to Fig.1b. Each timber was drilled with a 1.25-inch diameter hole approximately every four feet along its 18-foot length. Each mat had 4 such steel tension rods installed.

Each end of each tension rod was threaded and nuts were installed and tightened on the rods to approximately 200 foot-pound-force of torque. This level of torque tightened the individual timbers together such that they could behave as a composite panel. This concept is similar to that in stress laminated timber bridge decks. Mats were then flexurally tested per ASTM D5456-17 (2017) at a 17:1 span to depth ratio.
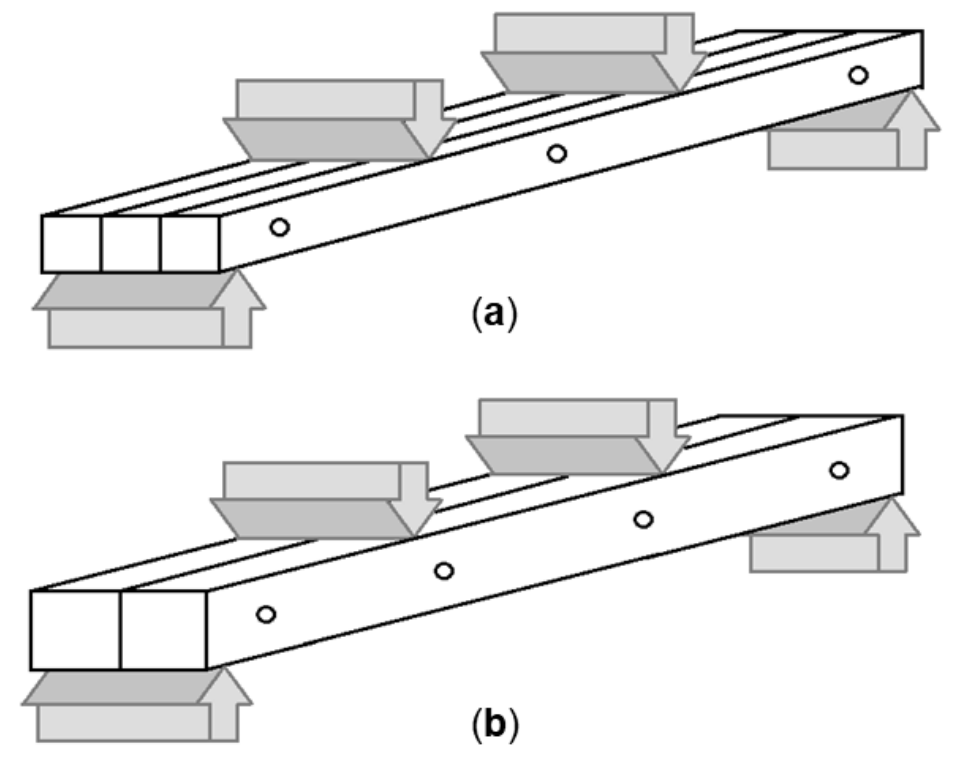

Fig. 1. Three-point flexural testing with line loading as applied to (a) three- and (b) two-member bolt-laminated mats

Figure 2 illustrates an exemplar mat in the test machine during destructive evaluation. In addition to the composite action created by the tension rods, the test fixture supported the mats and applied the loads across the width of the mat. In this manner, only the performance of the multi-timber composite, not that of the individual timber components, is considered.

The collected data were processed, and strength design values were statistically analyzed. This action included means calculation for MOE as well as parametric and nonparametric distribution analysis for MOR to determine the fifth percentile tolerance limits at the 75\% confidence level per ASTM D2915 (2010) as referenced by ASTM 5456 (2017). Analyses were performed using Statistical Analysis System (SAS) software version 9.4 (Cary, NC, USA). 


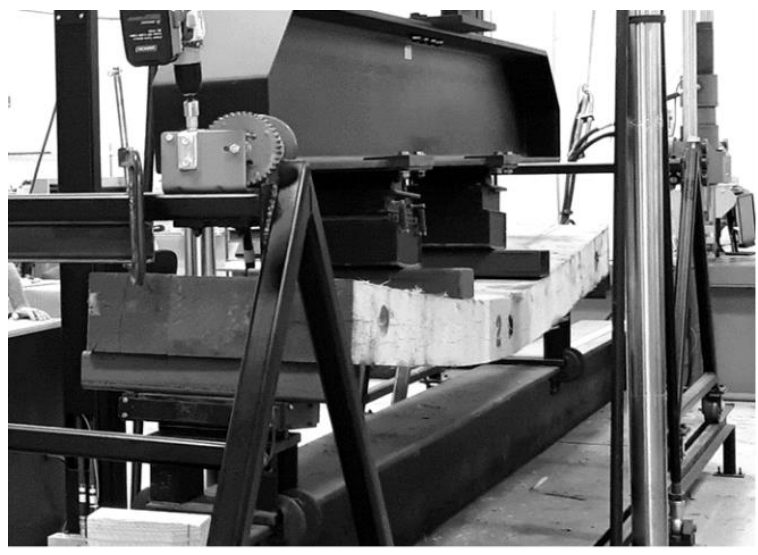

(a)

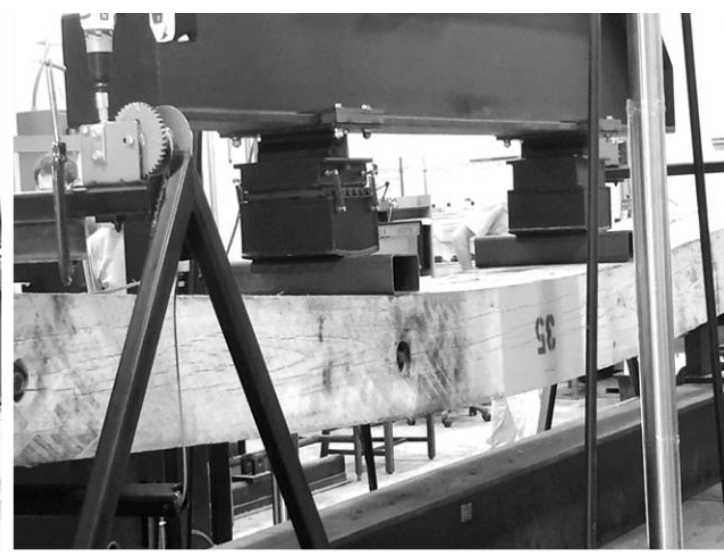

(b)

Fig. 2. Exemplar 8" deep, mixed oak (a) 3-piece and (b) 2-piece bolt laminated mat during destructive evaluation

\section{RESULTS AND DISCUSSION}

The performance of the 8-inch deep mixed oak mats is displayed in Table 1. The $F_{\mathrm{b}}$ allowable strength design values were 2,500 psi (parametric) and 2,415 psi (nonparametric). The average MOE was 1.43 million psi.

Table 1. Mechanical Strength and Stiffness Summary Statistics for 8-inch Deep, Tier 1 Mixed Oak Mats

\begin{tabular}{|c|c|c|}
\hline & $\begin{array}{c}\text { Modulus of Rupture } \\
\text { (MOR, psi) }\end{array}$ & $\begin{array}{c}\text { Modulus of Elasticity } \\
(\text { MOE, psi x 106 })\end{array}$ \\
\hline Number & 28 & 28 \\
\hline Average & 6549 & 1.43 \\
\hline Maximum & 8009 & 1.74 \\
\hline Minimum & 4869 & 1.20 \\
\hline Coefficient of Variation & $10.6 \%$ & $9.3 \%$ \\
\hline Non-parametric 5 $^{\text {th }}$ Percentile & 4869 & Not applicable \\
\hline$F_{\mathrm{b}}$ Design Value (Non-parametric) & 2415 & Not applicable \\
\hline Parametric 5 th Percentile & 5249 & Not applicable \\
\hline$F_{\mathrm{b}}$ Design Value (Parametric) & 2500 & Not applicable \\
\hline
\end{tabular}

Table 2. Mechanical Strength and Stiffness Summary Statistics for the 12-inch Deep, Tier 1, Mixed Oak Mats

\begin{tabular}{|c|c|c|}
\hline & $\begin{array}{c}\text { Modulus of Rupture } \\
\text { (MOR, psi) }\end{array}$ & $\begin{array}{c}\text { Modulus of Elasticity (MOE, } \\
\text { psi x 106) }\end{array}$ \\
\hline Number & 28 & 28 \\
\hline Average & 5955 & 1.33 \\
\hline Maximum & 7825 & 1.61 \\
\hline Minimum & 4125 & 1.04 \\
\hline Coefficient of Variation & $11.9 \%$ & $11.5 \%$ \\
\hline Non-parametric 5 $5^{\text {th }}$ Percentile & 4125 & Not applicable \\
\hline$F_{b}$ Design Value (non-parametric) & 2046 & Not applicable \\
\hline Parametric 5 $5^{\text {th }}$ Percentile & 4622 & Not applicable \\
\hline$F_{b}$ Design Value (parametric) & 2200 & Not applicable \\
\hline
\end{tabular}


The mechanical performance, MOR and MOE, of the 12-inch deep mixed oak (red and white groups) mats is shown in the Table 2 . The $F_{b}$ allowable strength design values were 2,200 psi (parametric) and 2,046 psi (non-parametric). The average MOE was 1.33 million psi. To the author's knowledge, this work represents the first of its kind attempt to assess the mechanical properties of both 8-and 12-inch deep mixed oak timber mats. Both the parametric and non-parametric design values herein can be compared to those of graded timbers as described in the National Design Specification (NDS 2018) for wood. As a comparison, per Northeastern Lumber Manufactures Association (NELMA), the $F_{\mathrm{b}}$ for No. 1 red oak in the post and timber size $(5 " \times 5$ " and greater) is 1000 psi. Adjusted for redundant members $\left(C_{\mathrm{r}}=F_{\mathrm{b}} \times 1.15\right)$, the $F_{\mathrm{b}}$ is 1150 psi. The MOE per NELMA for No. 1 red oak is 1.2 million psi. There are several key differences between this work and the existing published hardwood timber design values by NELMA (NELMA 2017). Firstly, the existing hardwood timber design values are meant for individual timbers that are graded per different criteria, i.e., based on the NELMA grade rules (NELMA 2017). Also, the NELMA values are based on small clear values that have been adjusted for size and grade.

The values determined herein are empirical and for composite mats comprised of timbers graded to a novel and experimental standard or criteria. The composite action elevates the strength values by load sharing, wherein stronger and weaker pieces often occur in the same mat, thereby limiting variability. With respect to MOR and MOE, the coefficients of variation (COV) for these mats were $10.6 \%$ and $9.3 \%$ respectively for the 8 -inch deep specimens and $11.9 \%$ and $11.5 \%$ respectively for the 12 -inch deep specimens. The analogous COVs for MOR and MOE of single members of clear wood are $16 \%$ and $22 \%$, respectively (Kretschmann 2010). These tighter distributions increase the statistical

$5^{\text {th }}$ percentiles that ultimately increase the $F_{\mathrm{b}}$ in design. Additionally, the action of testing actual size in-grade timbers perhaps provides more realistic performance values as compared to testing 2-inch deep, 28-inch-long small clear specimens and then adjusting them up to a volume that is on the order of 500 times larger $(58,752$ cubic inches per specimen for 12-inch deep mats as tested versus 112 cubic inches per specimen for small clear specimens). The work described herein includes a species group that is routinely selected for mat construction. Mixed oak timbers have a track record of favorable strength and wear properties which dates back 30 to 50 years. The values reported in this study are based on actual testing of full-scale timber mats. It is anticipated that future research work will include mats made from other timber species and at other depth values. Because the grading system used herein is developed by producers, this information can potentially be useful to describe the mechanical properties of timber mats as produced and deployed. Further research will allow crane mat industry to investigate alternative material, size, and structural design.

\section{CONCLUSIONS}

1. The experimental timber grading scheme employed herein resulted in mats that were highly uniform with respect to strength and stiffness.

2. The parametric and non-parametric strength values obtained from tested specimens equal or exceed those associated with single or redundant member graded timbers. This finding supports or encourages the use of the experimental grading criteria as well as full-scale testing. 
3. The characterization of timber mats strength and stiffness provides a starting point for producers and users to understand the performance and applications of their products.

\section{ACKNOWLEDGMENTS}

The authors wish to acknowledge the support of U. S. Department of Agriculture (USDA), Agriculture Research Service (ARS), under Agreement No. 58-0204-6-001. Any opinions, findings, conclusion, or recommendations expressed in this publication are those of the author(s) and do not necessarily reflect the view of the U. S. Department of Agriculture.

\section{REFERENCES CITED}

ASTM D2915-10 (2017). "Standard practice for sampling and data-analysis for structural wood and wood-based products." ASTM International, West Conshohocken, PA, USA.

ASTM D5456-17 (2017). "Standard specification for evaluation of structural composite lumber products." ASTM International, West Conshohocken, PA, USA.

Herberg, E. (2018). Flexural Performance of Nail-Laminated Timber Crane Mats, Master's Thesis, University of Minnesota, University Digital Conservancy, Minneapolis, MN, USA.

Kretschmann, D. E. (2010). Mechanical Properties of Wood, (GTR/FPL-190), U.S. Dept. of Agriculture, Forest Service, Forest Products Laboratory, Madison, WI, USA.

National Design Specification (NDS) (2018). National Design Specification for Wood Construction, American Wood Council, Washington, D.C., USA.

Northeastern Lumber Manufactures Association (NELMA) (2017). Standard Grading Rules for Northeastern Lumber, Northeastern Lumber Manufacturers Association, Cumberland, ME, USA.

Owens, F. C., Seale, R. D., and Shmulsky, R. (2020). "Strength and stiffness of 8-inch deep mixed hardwood composite timber mats," BioResources 15(2), 2495-2500. DOI: 10.15376/biores. 15.2.2495-2500

Shmulsky, R., and Shi, S. (2008). "Development of novel industrial laminated planks from sweetgum lumber," Journal of Bridge Engineering 13(1), 64-66. DOI: 10.1061/(ASCE)1084-0702(2008)13:1(64)

Shmulsky, R., Saucier, C. L., and Howard, I. L. (2008). "Composite effect of boltlaminated sweetgum and mixed hardwood billets," Journal of Bridge Engineering 13(5), 547-549. DOI: 10.1061/(ASCE)1084-0702(2008)13:5(547)

Stroble, III, M. F., Howard, I. L., and Shmulsky, R. (2012). "Wood construction platform design using instrumentation," Wood Material Science and Engineering 7(1), 13-24 DOI: $10.1080 / 17480272.2011 .637132$

Yang, B. Z., Shmulsky, R., and Seale, R. D. (2015). "Development of laminated planks from southern pine lumber," European Journal of Wood and Wood Products 73(4), 547-549. DOI: 10.1007/s00107-015-0915-z

Article submitted: Feb. 15, 2021; Peer review completed: Feb. 28, 2021; Revised version received and accepted: March 9, 2021; Published: March 17, 2021.

DOI: 10.15376/biores.16.2.3298-3303 